\title{
Sociedade civil e movimentos sociais: debate teórico e ação prático-política
}

\author{
Maria Lúcia Duriguetto \\ Universidade Federal de Juiz de Fora (UFJF)
}

Alessandra Ribeiro de Souza

Universidade Federal de Juiz de Fora (UFJF)

\author{
Karina Nogueira e Silva \\ Universidade Federal de Juiz de Fora (UFJF)
}

\section{Sociedade civil e movimentos sociais: debate teórico e ação prático-política}

Resumo: O artigo explicita a trajetória dos movimentos sociais na realidade nacional destacando sua relação com o Estado, as mudanças de suas formas de luta nos diferentes contextos históricos e os enfoques analíticos da relação entre sociedade civil e movimentos sociais produzidos. Na sequência, trata dos resultados iniciais de uma pesquisa em desenvolvimento acerca das características formativas, ideológicas e prático-políticas dos movimentos sociais existentes numa realidade municipal. A análise dos movimentos sociais na realidade nacional e dos resultados preliminares da pesquisa desenvolvida é norteada pela concepção de sociedade civil como espaço em que se desenvolvem os processos políticos que objetivam organizar os interesses das classes subalternas e projetá-los em termos de ação hegemônica na direção da construção de um novo projeto societário.

Palavras-chave: sociedade civil, movimentos sociais, realidade nacional, realidade municipal.

\section{Civil Society and Social Movements: Theoretical Debate and Practical Political Action}

Abstract: The article details the trajectory of the social movements in the national reality, highlighting their relationship with the State, the changes in their forms of struggle in different historic contexts and the analytical focuses of the relationship produced between civil society and social movements. It then analyzes the initial results of a study still underway of the formative, ideological and practical political characteristics of the social movements existing in a municipal reality. The analysis of the social movements in the national reality and of the preliminary results of the study undertaken is guided by the concept of civil society as a space in which political processes occur that seek to organize the interests of the subaltern classes and project them in terms of hegemonic action in the direction of the construction of a new social project.

Key words: civil society, social movements, national reality, municipal reality. 


\section{Introdução}

As temáticas da participação e do associativismo popular vêm constituindo um campo de debates na realidade nacional e latino-americana, sobretudo a partir do final da década de 1970. Esse campo temático e o crescimento das análises teóricas e prático-políticas estiveram, no processo histórico de seu desenvolvimento, fortemente ligados ao aparecimento e à multiplicação dos chamados "novos movimentos sociais". Situados no campo das demandas pelo acesso às políticas públicas, em suas diversas setorialidades, as organizações e os movimentos populares foram alvos de variadas perspectivas analíticas, tanto da academia quanto dos sujeitos que neles intervinham.

Partimos do entendimento de que a emergência e o desenvolvimento dos movimentos sociais, que expressam os interesses das classes subalternas, são o desdobramento sociopolítico das contradições do desenvolvimento capitalista que se materializam na chamada "questão social". . Foram os movimentos sociais que transformaram a questão social, na realidade brasileira e em qualquer outra formação social capitalista, numa questão política e pública. E é no campo da sociedade civil, tal como a definira o marxista italiano Gramsci, que se desenvolve a visibilidade política e pública da questão social pelos movimentos sociais. Sociedade civil, para Gramsci, é o espaço em que as classes organizam e defendem seus interesses (através de associações e organizações, sindicatos, partidos etc.), é a esfera da elaboração e/ou difusão de valores, cultura e ideologias que tornam, ou não, conscientes os conflitos e as contradições sociais. Portanto, é nela em que se confrontam projetos societários, em que se desenvolve a luta pela construção de projetos hegemônicos de classe.

A noção de "hegemonia" assume relevância central na formulação gramsciana de sociedade civil. A conquista progressiva de uma unidade político-ideológica - de uma direção de classe - requer a busca do consenso dos grupos sociais aliados, alargando e articulando seus interesses e necessidades. Desse modo, a própria ação de hegemonia exige uma práxis política consciente, coletiva e articulada das classes subalternas. Há, assim, uma dimensão nitidamente política no conceito gramsciano de sociedade civil, sua articulação dialética com a luta pela hegemonia e a conquista do poder por parte das classes subalternas (COUTINHO, 1991).

Explicitado o farol reflexivo do qual partimos para o entendimento dos movimentos sociais, necessário se faz um resgate sumário e esquemático do processo histórico da constituição da vida organizativa e participativa das classes subalternas, no campo da sociedade civil brasileira.

No Brasil, o padrão de intervenção estatal na consolidação da modernização capitalista conformou uma dinâmica social em que as ações e demandas das classes subalternas foram incorporadas sob a lógica da repressão, do clientelismo, do paternalismo e do autoritarismo. Esse traço da relação do Estado com as demandas e organizações das classes subalternas produziu, como expressão direta no plano político, a recorrente exclusão da participação popular nos processos de decisão política.

O caráter antidemocrático da nossa modernização capitalista teve no aparelho estatal um papel decisivo para a sua implementação, revelado pela exclusão da participação popular nos processos de decisão das questões políticas que ordenaram as relações entre Estado, classes dominantes e as classes subalternas. No dizer de Ianni (1984, p. 11) uma determinação constante do Estado brasileiro, independente de suas formas históricas assumidas, foi a "reiteração de soluções autoritárias, de cima para baixo, pelo alto" que colocaram a hegemonia dos interesses oligárquicos, burgueses e imperialistas no centro da organização estatal. Ou, de acordo com Coutinho (1991), esse traço antidemocrático da modernização política e econômica se expressava pela conciliação entre os interesses econômicos das frações das classes dominantes, pela mediação do poder estatal e pela exclusão das forças populares, que se dava seja pela via da repressão, seja pela da cooptação. Assim, todas as opções ligadas ao nosso processo de transição ao capitalismo foram construídas "pelo alto", de forma elitista e antipopular.

Coutinho (1991) utiliza da categoria gramsciana de "revolução passiva" como critério de interpretação do processo de transição do Brasil à modernidade capitalista. Em termos gramscianos, uma revolução passiva expressa a presença de dois momentos: rea- 
ção das classes dominantes à possibilidade de uma transformação efetiva de "baixo para cima"; reação que acaba por "restaurar" o equilíbrio precedente, ao mesmo tempo em que "renova" suas práticas sociais, antecipando-se a, ou incorporando e controlando "por cima", certas demandas populares com o que aumenta seu poder de controle e cooptação. Exemplo típico deste fenômeno de "renovação" é a legislação trabalhista brasileira, reivindicada ao longo das lutas sociais das duas primeiras décadas do século 20, que foi implantada junto com a imposição de dispositivos legais, que vinculavam os sindicatos ao aparelho estatal, anulando, assim, sua autonomia ${ }^{2}$.

Um aspecto desta exclusão política é, assim, a constituição da cidadania corporativa, sob a qual o Estado atrelava e subalternizava as demandas dos trabalhadores, criando uma ideologia de concepção dos direitos como doação de um Estado protetor. Como nos esclarece Telles (1999), ao invés de garantir e universalizar direitos, a arquitetura da cidadania corporativa destituiu indivíduos de suas prerrogativas de cidadania e produziu a fratura entre a figura do trabalhador e a do pobre incivil.

Nessa direção, segundo Santos (1998, p. 63), a cidadania, que denomina de "regulada", e a participação política, até os anos 1960, não constituíram resultado de um conjunto de valores políticos, mas da inserção ocupacional em uma das profissões reconhecidas pelo Estado.

A processualidade organizativa das classes subalternas assumiu características, em sua dinâmica interna, próprias dessas conformações que delinearam a relação do Estado com as vozes demandantes de direitos sociais.

No período que precedeu o golpe de 1964, o campo democrático e popular, sustentado na emersão de amplas camadas de trabalhadores urbanos e rurais sob a bandeira das "reformas de base", colocava em questão "a exclusão das massas dos níveis de decisão". A autocracia burguesa, na expressão de Florestan (1975), instalada com o golpe de 1964, reverteu o processo de democratização que estava em curso antes de 1964. Com esse redirecionamento, os sujeitos e as organizações políticas comprometidas com projetos nacionalpopulares e democráticos foram privados de qualquer mecanismo de mobilização, organização e representação (PAULO NETTO, 1991, p. 17).

Essa arquitetura de intermediação de interesses revela uma específica característica da relação do Estado com as agências da sociedade civil, "que expressam os interesses das classes subalternas", relação que vai em direção, segundo análise de Paulo Netto (1991, p.19), não de sobrepor a/ou impedir seu desenvolvimento, mas

[...] antes, consiste em que ele [Estado] tem conseguido atuar com um vetor de desestruturação, seja pela incorporação desfiguradora, seja pela repressão [servindo, assim] de eficiente instrumento contra a emersão, na sociedade civil, de agências portadoras de vontades coletivas e projetos societários alternativos.

Essa constatação do padrão de relações entre o Estado e as organizações situadas no arco de defesa de demandas e interesses das classes subalternas sofrem uma inflexão, a partir do final da década de 1970, em que se assiste a um adensamento e a uma proliferação de movimentos e organizações sociais, principalmente nas grandes cidades. Neste quadro conjuntural, assiste-se à redução da dependência dos movimentos sociais da tutela estatal e a um crescimento das associações comunitárias, aos movimentos pela defesa de demandas por direitos civis, políticos e sociais, à defesa de autonomia organizacional em relação ao Estado, ao reaparecimento e expansão das organizações sindicais e à criação de novos partidos etc. (BOSCHI, 1987).

As produções acadêmicas e a prática sociopolítica destes movimentos apresentavam, como substrato teórico comum, uma perspectiva oposicionista na relação entre sociedade civil, mediada pelos movimentos sociais, e Estado. Assim, todas as expressões da sociedade civil passaram a ser vistas de uma forma positiva, pois eram entendidas como tudo aquilo que se contrapunha ao Estado, o lado negativo (DURIGUETTO, 2001).

A partir da segunda metade da década de 1980, particularmente no contexto da assembleia constituinte, evidencia-se um direcionamento das ações dos movimentos sociais para a institucionalização de suas relações com as agências estatais, vistas como campo estratégico de demandas por direitos de cidadania. Essa estratégia é, também, visualizada para a ampliação da democracia, que se daria pela criação de canais político-institucionais para a participação dos cidadãos nos processos de discussão e negociação de políticas públicas, especialmente pela criação dos conselhos de direitos.

Neste cenário de redefinição das ações práticopolíticas dos movimentos sociais, parece consensual a constatação do abandono de atitudes de confronto e de reivindicação pela valorização de condutas institucionais pragmáticas e propositivas na busca de diálogo, negociação, parcerias com o Estado e de formas alternativas de participação no sistema de representação de interesses. Essa redefinição das formas de luta dos movimentos sociais fomentou a elaboração de análises, nas quais emerge uma nova concepção de sociedade civil. Esta passa a ser entendida como a esfera, na qual se desenvolve uma articulação entre os movimentos sociais e as agências estatais por espaços democráticos de representação e interlocução pública para o reconhe- 
cimento, garantia e consolidação de direitos de cidadania $^{3}$ (DAGNINO, 1994).

No entanto, os avanços legislativos no campo dos direitos sociais e da participação popular, na sua formulação e fiscalização, contidos na Constituição foram fortemente atacados, a partir dos anos 1990, pela ofensiva neoliberal. Ofensiva que se materializa, nessas quase duas décadas, pelas mudanças requeridas pelo processo de reestruturação produtiva e pelo desmonte da regulação estatal no campo da economia e dos direitos sociais formalmente garantidos em 1988 .

Para as classes e camadas subalternas, as mudanças no mundo do trabalho - crescente complexificação do uso, remuneração e dispensa da força de trabalho (flexibilização, informalização, subcontratação e desemprego) - vêm resultando em uma maior complexificação da sua morfologia, caracterizada por uma heterogeneização, uma composição segmentada e pulverizada dos trabalhadores. E vêm se expressando, também, na segmentação da organização sociopolítica em seu interior, em que milhares de trabalhadores são postos numa situação de excludência, no que concerne a medidas que favoreçam a formulação de direitos relacionados às suas necessidades e aos seus interesses (ANTUNES, 1999).

Em relação às suas organizações, observa-se a construção de formas de sociabilidade marcadas por iniciativas pragmáticas de ação, que vem produzindo uma fratura de suas formas históricas de organização, esgarçando uma cultura política que comportava alternativas à ordem do capital (ALVES, 2005).

A esfera estatal, na sua regulação social, particularmente no campo das políticas sociais, vem, também, imprimindo uma segmentação do acesso das classes subalternas aos padrões das políticas, marcando o universo dos consumidores dos serviços oferecidos pela via mercantil e o dos beneficiários das políticas públicas, focalizadas ou das ofertadas pelo chamado "terceiro setor"4.

É neste chamado "terceiro setor" que o Estado, sob o ideário neoliberal, opera uma ressignificação do conceito de sociedade civil. O Estado passa a investir na participação da sociedade civil, mas não na direção do controle social na gestão e implementação das políticas sociais como demandado pelos movimentos sociais, mas na direção de transferir a ela o papel de agente do bem-estar social. Sociedade civil é aqui transformada em uma esfera supostamente situada para além do Estado e do mercado, cabendo a ela uma atuação na área social, sob o invólucro da solidariedade, da filantropia e do voluntariado. Ou seja, há, aqui, um esforço ideológico de despolitização da sociedade civil, concebendo-a como reino da "a-política" e do "a-classismo".

Este cenário de privatização das políticas - seja na sua oferta cada vez mais avassaladora e abran- gente pelo setor privado, seja pelo incentivo crescente de sua oferta pelo terceiro setor - e de sua oferta compensatória vem imprimindo um conteúdo despolitizador nas ações reivindicativas dos movimentos sociais e restrito aos limites da particularidade de grupos sociais diversos. Em outras palavras, em relação às organizações e aos movimentos que defendem e representam os interesses das classes subalternas, a ofensiva neoliberal vai em direção de submetê-las à lógica do mercado, à despolitização e fragmentação das suas lutas e demandas, orientando-as para a defesa de interesses puramente corporativos e setoriais ${ }^{5}$.

Expostas as determinações sócio-históricas e ideopolíticas regressivas que vêm conformando o processar das ações das organizações e movimentos sociais das classes subalternas, queremos agora, tratar de uma questão problemática do campo da análise dos movimentos sociais.

O investimento dos movimentos sociais - em suas diversas expressões organizativas e variedade de demandas - no campo da luta institucional, a partir da segunda metade dos anos 1980, foi, também, acompanhado por uma forte tendência de substituição do enfoque analítico nos sujeitos sociais - e suas posturas ideopolíticas e prático-organizativas - para um enfoque das políticas públicas e da participação dos sujeitos e das organizações populares em seu interior. Ou seja, uma forte tendência a substituir a temática dos movimentos sociais pelo desenho das políticas públicas. Pensamos que essa protagonização no campo das políticas e dos espaços institucionais que agrega, acaba, quando muito, secundarizando o conhecimento e o desvelamento do universo da vida social, cultural e organizativa da população - suas condições de vida, de trabalho, suas expressões culturais, suas demandas e aspirações, formas de ações e organizações políticas utilizadas e/ou que se encontram envolvidos. Isso possibilita apreender suas formas de luta, demandas e condutas para além de sua expressão nos espaços institucionais. É nessa direção que concordamos com Ribeiro (2001, p. 11), na necessidade da busca tanto de "parâmetros que valorizem os sujeitos" quanto de "reconhecimento das condições materiais e político-institucionais de sua manifestação no espaço público. Trata-se, portanto, da reunião das condições objetivas às condições subjetivas da ação social." É essa "dupla face" analítica da ação dos sujeitos que pode possibilitar a apreensão de sua "capacidade de organização" e da dimensão “ideopolítica” que a caracteriza. É essa orientação, associada às determinações macroestruturais do ideário neoliberal e seus impactos nas organizações e movimentos sociais das classes subalternas, que nos conduziu para a investigação das formas de organização e de participação popular na realidade municipal de Juiz de Fora. 


\section{Metodologia}

Podemos verificar que a maior parte das análises desenvolvidas acerca dos movimentos e associações é baseada em metodologias qualitativas. Acreditamos que as análises e debates sobre as formas de participação e de associativismo ganham em qualidade quando, também, dispomos de dados empíricos, dos quais o caso brasileiro e, particularmente as realidades municipais, são especialmente carentes (LANDIM, 2005).

A pesquisa foi desenvolvida, inicialmente, nas Regiões Administrativas Sul e Sudeste do município ${ }^{6}$. A coleta de dados foi realizada pela pesquisa de campo, através das técnicas de questionário, entrevistas e pesquisa documental. A pesquisa de campo foi baseada na pesquisa $O$ associativismo na cidade de São Paulo, realizada em 2004.

Nesta pesquisa, a coleta constituiu na aplicação de um questionário, com perguntas abertas e fechadas, em que se objetivou apreender o percentual de população associada, características do conteúdo e das formas de participação (precisando a filiação formal e informal), variação das formas de participação etc. A definição de participação foi baseada no critério da frequência de atividades coletivas realizadas pelos sujeitos no último ano; na formalidade e informalidade da participação, sendo a participação formal definida pela necessidade de algum processo protocolar obrigatório para o seu reconhecimento como membro da associação; e, por fim, as associações a que pertencem.

As associações foram divididas nas seguintes áreas e temas de atuação:

a) associações civis, que tratam da tematização e solução de questões comunitárias (ligadas à questão de moradia, saúde e educação);

b) associações relacionadas ao mundo do trabalho;

c) associações ligadas aos direitos de cidadania para segmentos sociais específicos;

d) associações filantrópicas e de auto-ajuda, culturais e de grupos de jovens, e as religiosas.

O questionário foi estruturado em duas partes. $\mathrm{Na}$ primeira, a caracterização socioeconômica do entrevistado e sua família, abrangendo questões como escolaridade, cor, renda, inserção no mercado de trabalho, sexo etc. Na segunda, a caracterização da participação. Em relação aos que participam, foram consideradas questões que permitissem traçar o perfil desta participação, como, por exemplo, em que tipo de grupos/associações os sujeitos têm se inserido, a formalidade da vinculação a estes espaços, os objetivos e as atividades às quais se dedicam; o processo de tomada de decisões; os motivos da participação e seus resultados e impactos sociopolíticos.

A aplicação do questionário foi realizada com base na definição de critérios estatísticos para delimi- tar a amostragem e definir os domicílios a serem entrevistados. O levantamento da população residente nos bairros foi realizado junto às suas respectivas Unidades Básicas de Saúde. Em cada bairro, foram aplicados 96 questionários, totalizando 384 entrevistas ${ }^{7}$.

\section{Resultados da pesquisa de campo}

Os entrevistados que afirmaram participar, atualmente, de algum grupo ou associação representam $24,5 \%$ do universo pesquisado. Se considerarmos aqueles que não participam atualmente, mas participaram no último ano, essa taxa sobe para $28,6 \%$. Os que nunca participaram representam $61,5 \%$ dos entrevistados que, somados aos que não participam, mas já participaram há mais de um ano, totalizam 71,4\% dos entrevistados.

As principais características dos participantes de grupos ou associações expressam-se nos percentuais a seguir. Aproximadamente, $60 \%$ têm renda familiar de até três salários mínimos e estão precariamente inseridos no mercado de trabalho; $19,8 \%$ estão desempregados e $45,8 \%$ estão empregados (o restante se divide entre estudantes, aposentados e donas-de-casa). Dos que estão empregados, $31,8 \%$ não possuem vínculo formal de trabalho, ao passo que $68,2 \%$ estão no mercado formal. A escolaridade dos membros dessas associações é baixa, $44,8 \%$ têm apenas o ensino fundamental incompleto e somente $4,2 \%$, o ensino superior.

Entre aqueles que participam de grupos e associações atualmente, $67,3 \%$ exercem sua participação em instituições religiosas, $26,3 \%$ em associações civis (culturais, filantrópicas, recreativas, comunitárias, conselhos de direitos) e 1,8\% em sindicatos.

Uma vez determinado o percentual da participação geral, partimos para a caracterização da dinâmica interna do funcionamento das associações e das características da participação. No que se refere à frequência da participação dos sujeitos nas atividades desenvolvidas pelas associações, os dados revelam um alto grau de envolvimento por parte dos associados, uma vez que $54,3 \%$ disseram participar uma ou mais vezes por semana das suas associações.

As atividades mais frequentes realizadas nas associações são reuniões, $25,5 \%$, seguidas de atividades características de instituições religiosas como missa, grupo de oração, estudo bíblico etc., 29,8\%. A seguir estão as dinâmicas de grupo, $13,8 \%$, e atividades culturais, recreativas e físicas, $16 \%$. Os demais entrevistados colocaram como as atividades mais frequentes das associações e grupos dos quais participam: a distribuição de materiais e doações a carentes, 7,4\%; a discussão de políticas públicas, $4,3 \%$. Entre eles, 32,\% não souberam informar.

Relacionando a participação e a principal atividade desenvolvida pelas associações, podemos perce- 
ber que as práticas de reuniões e dinâmicas de grupos foram os resultados mais frequentes entre as associações religiosas e as civis, já entre as sindicais as atividades mais frequentes foram as reuniões e a discussão de políticas públicas.

Com o objetivo de aferir os motivos da participação e seus resultados, perguntamos para os associados acerca dos conteúdos materiais e simbólicos conquistados com a ação participativa. 77\% dos respondentes ressaltaram que a principal vantagem com a participação foi o despertar para a solidariedade, para o amor ao próximo e ganhos espirituais. Uma pequena percentagem destacou outros elementos: $11,4 \%$ disseram ter aprendido a defender seus interesses e a ter ganhos materiais; e apenas 3,2\% destacaram o ganho de uma consciência política.

No entanto, uma contradição é revelada, se refletirmos acerca desse bônus da participação em relação ao conteúdo das respostas dos entrevistados, quando perguntados se a participação os ajudou a compreender melhor o funcionamento do governo e dos órgãos públicos. $60 \%$ afirmaram uma relação positiva entre a ação nas associações e esse aprendizado político. O que podemos inferir dessa constatação é que a participação traz conteúdos de aprendizagem política, mas esse conteúdo não é ressaltado como o principal da participação e sim os benefícios espirituais e individuais.

Devido à relevância da participação em instituições religiosas, explicitaremos algumas características dos sujeitos que a definem como seu campo associativo. Entre aqueles que estão associados a instituições religiosas, a maioria está ligada à Igreja Católica. A estes, seguem-se os ligados às igrejas evangélicas. E, entre todos esses, em menor número, encontram-se os adeptos do espiritismo.

Algumas características desses participantes de grupos religiosos chamam a atenção: $41,9 \%$ não completaram o ensino fundamental e $4,1 \%$ possuem o ensino superior. No que tange à renda, a maioria dos participantes de grupos vinculados a instituições religiosas recebe até três salários, porém um dado significante merece ser mencionado: entre aqueles entrevistados que têm renda familiar de cinco ou mais salários mínimos e que participam de algum grupo ou associação, 75\% responderam participar de associações religiosas.

Os números relativos à inserção no mercado de trabalho dos participantes de associações religiosas destoam daqueles relativos à participação geral: mais participantes de associações religiosas estão desempregados em relação ao total dos participantes. Dos que estão nas associações religiosas 40,5\% estão empregados (contra 45,8\% da participação geral) e 24,3\% desempregados (contra 19,8\% da participação geral). De encontro a esses dados, constatamos que o número de trabalhadores que possuem vínculo empregatício está acima da média dos participantes em geral: $73,3 \%$ possuem vínculo empregatício ao passo que $26,7 \%$ não possuem.

Com o objetivo de caracterizar o que impulsiona os participantes a atuarem em determinadas associações, aplicamos um conjunto de questões que buscaram ilustrar os principais objetivos das entidades nas quais os respondentes participam.

Os resultados obtidos mostram que a participação em associações de tipo religioso está voltada para experiências coletivas de ação social. Entre os objetivos das associações religiosas, os mais presentes nas respostas dos entrevistados são os referentes à doação aos necessitados, havendo, ainda, uma porcentagem considerável daqueles que disseram ser a busca de melhorias para a comunidade e a defesa dos direitos dos seus moradores.

Os objetivos das ações e das atividades das associações civis que envolvem a participação dos entrevistados são diversos, mas, ao mesmo tempo, similares no arco das atividades desenvolvidas. Dentre os participantes das associações civis (26,3\%), destacamos que a participação em associações de moradores representa $10,6 \%$ dos que participam atualmente. Dos que participam dessas associações, 58\%, evidenciaram ser a luta por melhorias para a comunidade o principal objetivo de suas ações; $16,7 \%$ definiram a ação assistencial para crianças e adolescentes; $16,7 \%$ identificaram a defesa dos direitos dos trabalhadores e $8,3 \%$ a doação a pessoas carentes.

A participação em associações culturais representa $9,6 \%$ do total dos que participam das associações civis atualmente. Os objetivos identificados foram: $11,1 \%$ evidenciaram melhorias para a comunidade; 11,1\% ajuda emocional; 22,3\% assistência para criança e adolescentes e $55 \%$ definiram que os objetivos de suas intervenções são todos os acima elencados.

É interessante observarmos que os mesmos objetivos das associações culturais são identificados como o centro das atuações das associações filantrópicas. Participam destas associações, 2,5\% do total dos entrevistados. A totalidade dos pertencentes às instituições filantrópicas apontou a ajuda emocional, assistência para crianças e adolescentes e doação a carentes como seus principais alvos de ação.

As associações recreativas representam 4,4\% do universo dos que participam de associações. Para 80\%, os objetivos da intervenção são melhorias para a comunidade e $20 \%$ identificaram a ajuda emocional.

Os Conselhos de Direitos também representam o mesmo universo dos respondentes que participam $(4,4 \%)$ e $100 \%$ dos que estão inseridos nesse desenho de participação institucional responderam que seu principal objetivo é promover melhorias para a comunidade.

É possível perceber, pelos objetivos de atuação das entidades civis identificados, que o universo dos sujeitos que participam expressa uma atuação movi- 
da tanto por objetivos que constituíram as ações dos movimentos e associações destas regiões (lutas por melhorias de infra-estrutura, pela melhoria na qualidade dos serviços de saúde e habitação), quanto por objetivos que se situam no campo de ações assistenciais materiais - ação de doação - e psicossociais - ajuda emocional.

As associações sindicais representam 1,4\% dos respondentes que participam. A totalidade dos respondentes situa a defesa dos direitos dos trabalhadores como o principal motivo da ação sindical.

No que se refere à participação sindical, observamse algumas características que não correspondem às da participação de um modo geral. Dos participantes de sindicatos $(1,4 \%), 50 \%$ não completaram o ensino fundamental e outros $50 \%$ possuem curso superior, média maior que a da participação geral. A renda familiar de $50 \%$ dos associados é de até três salários mínimos, os outros $50 \%$ possuem renda de cinco a dez salários.

Aqueles que compõem a categoria de associativismo civil possuem relativamente, menor escolaridade: $50 \%$ têm ensino fundamental incompleto e apenas 2,9\% possuem curso superior, sendo estes participantes de Conselhos de Direito. A inserção social dos participantes no mercado de trabalho é precária: $61,1 \%$ dos seus participantes estão no mercado informal. Quanto ao gênero, trata-se de uma participação predominantemente feminina: $69,7 \%$ dos participantes são mulheres.

Apesar de representar a forma de associativismo mais presente entre os entrevistados, quando questionados sobre qual o grupo ou associação gostariam de participar, o interesse pela participação em instituições religiosas representou uma porcentagem muito menor que o interesse por associações civis. Nestas, entre aqueles que não participam atualmente, mas gostariam de participar, 28,6\% apontaram as associações de moradores como espaços associativos em que gostariam de atuar.

Uma hipótese explicativa para esse dado pode ser encontrado em outro resultado da pesquisa referente às associações que já convidaram os entrevistados a participar. A maioria daqueles que foram convidados obtiveram tal convite de associações religiosas, demonstrando o empenho dessas instituições em buscar novos associados.

Considerando que as formas de inserção em espaços de participação são variadas, a pesquisa buscou captar, além da participação formal, a informal. Entre aqueles que participam atualmente, 52,1\% disseram não possuir vínculo formal com suas respectivas associações e grupos. Observamos que, nas associações religiosas, há a predominância de vínculos informais com seus participantes, caracterizando 55,4\% da ação dos sujeitos participantes. Também evidenciamos uma taxa alta da participação informal no universo das associações civis. Mais da metade dos seus participan- tes, 52,9\%, afirma não ter vínculos formais de adesão com a associação da qual participam.

\section{Considerações e desafios}

A temática da participação popular tem sua expressão material num plural e diversificado mundo associativo, criado e desenvolvido pelas classes subalternas no campo da sociedade civil.

Enormes desafios se impõem no tempo presente para a construção de processos ideo-políticos e práticoreivindicativos que direcionem a consciência e as ações das classes subalternas no campo da sociedade civil para a formação de uma contra-hegemonia e de um projeto societário de efetiva intervenção anticapitalista. Esse desafio é revelado tanto pela configuração contemporânea dos movimentos sociais na realidade nacional quanto pelas características explicitadas acerca das formas e dos conteúdos da participação das classes e camadas subalternas na realidade municipal.

Uma análise inicial dos dados da pesquisa revela a configuração de organizações e formas de participação inteiramente despolitizadas e despolitizadoras, particularmente por preponderar uma cultura associativista religiosa cujos ganhos de pertencimento são o do crescimento e enriquecimento espiritual e o do desenvolvimento da solidariedade. Percebe-se, ainda, a inexistência de movimentos sociais, capazes de colocar em pauta algo mais que reivindicações imediatas, pontuais e particularistas, centradas em demandas por serviços que compõem o campo das políticas sociais. Essa realidade organizativa apresenta uma forte sintonia tanto com os conteúdos definidos para a sociedade civil pelo neoliberalismo (que a concebe como um campo ético-moralizante) quanto pelos que a concebem como campo de direitos de cidadania.

Nossa intenção, com a apresentação dos resultados iniciais da pesquisa, é a de apresentar indicações que permitam delimitar campos de reflexão e análise que possam ser explorados, posteriormente, de forma sistemática e rigorosa ${ }^{8}$. A pesquisa está sendo desenvolvida nas outras três regiões administrativas da cidade, o que permitirá o desenvolvimento de uma análise totalizante da propensão associativa, da variação das formas de participação, das agendas com maior potencial mobilizador e traçar o perfil das pessoas que participam, no município.

Os conteúdos informativos dos dados levantados na realidade municipal e as regressividades explicitadas no campo dos movimentos sociais na realidade nacional revelam um grande desafio para alimentar o "otimismo da vontade": a construção, pelas classes e camadas subalternas, de uma visão integrada de suas necessidades, interesses, reivindicações e ações prático-políticas, incorporando-as em um quadro abrangente e classista. 


\section{Referências}

ALVES, G. O novo (e precário) mundo do trabalho. São Paulo: Boitempo, 2005.

ANTUNES, R. Os sentidos do trabalho. São Paulo: Boitempo, 1999.

AVRITZER, L. A participação em São Paulo. São Paulo: Unesp, 2004.

BOSCHI, R. R. A arte da associação. Rio de Janeiro: Vértice, 1987.

COUTINHO, C. N. Gramsci. Um estudo sobre seu pensamento político. Rio de Janeiro: Campus, 1991.

DAGNINO, E. Os movimentos sociais e a emergência de uma nova noção de cidadania. In: (Org.). Os anos 90: política e sociedade no Brasil. São Paulo: Brasiliense, 1994.

DURIGUETTO, M. L. A teoria dos movimentos sociais em debate. Revista Libertas, Juiz de Fora, v. 1, n.1, p. 67-84, jan./jun. 2001.

Sociedade civil e democracia: um debate necessário. São Paulo: Cortez, 2007.

FLORESTAN, F. A revolução burguesa no Brasil. Rio de Janeiro: Zahar, 1975.

IANNI, O. O ciclo da revolução burguesa no Brasil. Petrópolis: Vozes, 1984.

LANDIM, L. Associações no Brasil: comentários sobre dados oficiais recentes. Revista Democracia Viva, Rio de Janeiro, n. 28, ago./set. 2005.

MONTAÑO, C. Terceiro setor e a questão social - crítica ao padrão emergente de intervenção social. São Paulo: Cortez, 2002.

PAULO NETTO, J. Ditadura e Serviço Social. São Paulo: Cortez, 1991.

RIBEIRO, A. C. T. Leitura de movimentos: conjuntura, ação e poder. Revista Temporalis, São Paulo, ano II, n. 4, p. 9-19, julho/dez, 2001.

SANTOS, W. G. A pós-revolução brasileira. In: JAGUARIBE, H. et al., Brasil, sociedade democrática. Rio de Janeiro: José Olympio, 1995.

Décadas de espanto e uma apologia democrática. Rio de Janeiro: Rocco, 1998.
SETÚBAL, M. Expressões do conflito social contemporâneo. Disponível em: $<$ http://www.outrobrasil .net>. Acesso em: 11 jun. 2007.

TELLES, V. Direitos sociais - Afinal do que se trata? Belo Horizonte: Editora UFMG, 1999.

\section{Notas}

1 Entendida como expressão das contradições advindas das relações sociais de produção e das lutas dos trabalhadores que conferem visibilidade a essas contradições.

2 Para especificação da relação dos conceitos de "via prussiana" e "revolução passiva" e o processo de modernização capitalista brasileiro, cf.Coutinho(1991,p. 119-136).

3 Para uma análise crítica da ressignificação do conceito de sociedade civil, consultar Duriguetto (2007).

4 Para uma discussão da funcionalidade do chamado terceiro setor para o neoliberalismo, ver Montaño (2002).

5 No entanto, com base no reconhecimento de algumas experiências organizativas, especialmente as que objetivam articular, na luta urbana e rural, sujeitos sociais diversos, na sua maioria expulsos do circuito do mercado formal, é possível argumentar que diferentemente do que tem sido, por vezes, afirmado na análise dos movimentos sociais, a conjuntura atual não é marcada única e exclusivamente pelo crescente refluxo destes, tampouco nos encontramos frente à tendência ao desaparecimento dos movimentos sociais, orientados por um projeto de classe. Começa a ganhar volume um descontentamento pela esquerda, de setores dos movimentos sociais, que tem promovido ações de maior confronto político e programático. Cf. Setúbal(2007).

6 Juiz de Fora se divide em oito regiões administrativas. A pesquisa será realizada em todas as regiões. A amostra foi selecionada de forma estratificada por cada uma das oito regiões, considerando-se uma margem de erro de $10 \%$ no valor do estimador amostral das regiões. Dessa forma, esperase que o estimador para o total do município apresente margem de erro máxima de 2,5\%. Dentro de cada região administrativa, os domicílios foram sorteados seguindo um procedimento de amostragem sistemática.

7 A seleção da amostra seguiu os seguintes estágios: seleção dos setores censitários e seleção dos domicílios; eleição sistemática de 10\% dos domicílios, nos setores incluídos na amostra. Para o sorteio dos domicílios, foram utilizados uma folha de listagem, com número aleatório entre um e dez, que indicava a primeira casa sorteada, sendo o entrevistador orientado para selecionar a décima casa após a primeira, e assim sucessivamente, até a cobertura completa do setor, sempre em sentido horário. 
8 A pesquisa identificou a necessidade de um estudo aprofundado acerca das formas organizativas que compõem o universo associativo nas regiões pesquisadas, como por exemplo, as associações de moradores.

\section{Maria Lúcia Duriguetto}

Doutorado em Serviço Social pela Universidade Federal do Rio de Janeiro (UFRJ)

Professora da Faculdade de Serviço Social da Universidade Federal de Juiz de Fora (UFJF)

\section{Alessandra Ribeiro de Souza Karina Nogueira e Silva \\ Bolsistas de Iniciação Científica}

\section{UFJF - Faculdade de Serviço Social}

Campus UFJF

Bairro Campus Universitário

Juiz de Fora - Minas Gerais

CEP: 36001-970 